\title{
TURKEY-EUROPEAN UNION RELATIONS AFTER THE HELSINKI SUMMIT*
}

\section{İsmail CEM**}

\author{
President of Marmara University, \\ Esteemed Lecturers, \\ Dear Guests and Dear Students,
}

It is my pleasure to be with you today for the commemoration of Europe Day. Looking at the faces of all the young people in this hall, I am sure that the future is shared by young people who have high expectations regarding their futures. The European Union is of course the project of our future. It is a project; a design that will determine the future of the whole of Europe including Turkey. The preceeding speakers have repeatedly emphasised the European Convention and Turkey's contribution to it. This is for sure because if the Convention is to shape the future of Europe, Turkey is present in this future and she has a say in it. Turkey has to make a contribution if she wants to participate in this future. In other words, the degree to which Turkey takes part in the future of Europe depends on her contribution.

In addressing this distinguished audience, let me define what would be the ideal context for Turkey-European Union relations. It is imperative to clarify some specific points as well as considering the functions of both Turkey and the EU and to eliminate certain mistakes if we want to develop relations in a better and more rapid way. First of all, EU membership is one of the two main goals of this country in the first decade of this century. The other goal is to become a country that is central, powerful, effective and

* Speech for the international conference entitled "The Future of the European Union and Turkey" organized by the European Community Institute of Marmara University on the occassion of the Europe Day, 9 May 2002.

** Minister of Foreign Affairs of Turkey. 
determinant to the developing geography of Eurasia. I clearly defined and proposed these two goals in a press conference given during the early days of my tenure as foreign minister in order to explain our future perspective and to reveal how it would shape our foreign policy. These goals centre on the European Union on the one side and Eurasia on the other. The latter comprises a large geographical area from Eastern Europe to the steppes of Central Asia and is a focal point where new energy resources and new strategic positions are located. Turkey is definitely committed to asserting itself in this area as on the issue of EU membership. It could be debated by some as to whether these two goals conflict with each other. The answer is definitely no. These goals mutually reinforce each other. I assure you that the greatest impact of Turkey's EU candidacy status declared at the Helsinki Summit was on countries in the Middle East; the Gulf and in Central Asia. Immediately after Helsinki, during my official visit to these regions I personally witnessed Turkey's improved image. These countries stated that they consider Turkey to be a facilitator; a bridge and a friendly country in their relations with the European Union.

All these wishes have become reality. This has been the case in the BakuTbilisi-Ceyhan oil pipeline project or in the Middle East peace processespecially Israel during the period in which Barak's government was in charge. I observed that Turkey had become more effective and her voice is better heard in EU circles. In other words, Turkey possesses a distinct and special position. Turkey, as both a European and an Asian country has assimilated the cultures of both because it possesses the historical and cultural aspects of a large geography extending from Balkans to the Caucuses; the Middle East; the Gulf and Central Asia. There are only a few countries in the world that possess the same characteristics and have became historically dominant and able to reflect the cultures of various civilisation. Russia in the East-West-Asia-Europe axis could be cited as an example. Indeed, Russian literature addresses this vital question of identity as to whether Russians are European or Asian. This is understandable because Russia like Turkey, is a country which has been able to assimilate and reflect the exceptional advantages of two separate civilisations.

Turkish people have to consider the future of Turkey-EU relations by accepting the fact that these two characteristics are not mutually exclusive but reinforce each other. There was a common fallacy -to which I severely objected- although it is rarely observed today: "When we accede to the 
European Union our Europeanness will be proven". I object to the idea that "only membership will certify that Turks are European". Who will certify it? It was of course a fallacy. I personally and the Foreign Ministry as a whole have struggled against this fallacy for the last five years and it has become obsolete. What does it mean "to be European"? If the criterion is related to history or geography, then historical geography of Turkey can largely be concerned with Europe. Currently, a significant part of Turkey's territory, though smaller in area to the rest lies in Europe. If being European is a historical matter, then it should be noted that almost all of our history during the last seven centuries took place in Europe as a European power. This is what the history books tell us. Turkey has been accepted as a "European Power". Our history is surely a European history. Turkish history took place in Kosova, in Bosnia and in Manastir as well as in Bursa, Kayseri, Konya, Diyarbakir or in Trabzon. I mean that the history of Turkey is at the same time a European history.

If Europe is to be defined by cultural attributions then we have to make a more delicate analysis. If Europe is defined by "judeo-christian" values or in ethnic terms, the Turks are not a part of it. If Europe is to be defined in terms of the values of democracy, human rights, pluralism, equality between men and women, secularism as asserted by the European Union and the Council of Europe based in Strasbourg, Turkey is a part of Europe although it is true that we have experienced some delays in realising these values. Turkey is not only a part of this culture but also possesses some of these characteristics more than some other European countries. If European culture is a culture of pluralism, tolerance and diversity, we have historically possessed such features. Europe has been a place where millions of people were massacred for religious or ethnic purposes; ninety thousand people-sixty thousand of whom were women- have been killed over three centuries solely for their beliefs or different life styles. Turkey created an atmosphere of tolerance during this era and has made a manifest contribution to the history of mankind in acquiring contemporary values. Turks have been European for seven hundred years. Therefore, accession to the European Union is not a proof of Europeanness for Turkey. What will EU membership provide for Turkey? What do we expect from EU membership?

Before I evaluate this in detail let me mention a few misunderstandings. Some in Turkey claim that "the EU will never accept Turkey as a full member, so let us not work for it. The idea of Turkish accession to EU is a deceptive illusion". Some others claim that "the EU will eventually accept 
Turkey and indeed must do so, therefore there is no need to be in a hurry". These approaches are both abstract and are consequently false. The EU's relationship with Turkey is based on mutual interests as is common in foreign relations. Thus it is a sound relationship. What is important is not to love, admire or hate the Turks. The criteria is based on interests which I believe to be the right ones.

The European Union accepts the idea of Turkey as a full member because Turkey's participation is in its own interests. Turkey wants to join the EU because she has interests as well. The EU accession process and membership is a valuable exogenous motivation-a dynamic means-for Turkey to achieve future objectives. EU membership is a logical and rational step in economic, political, social and even in inter-personal relationships. Being a part of this logic as a candidate and eventually a member country will provide Turkey with the possibility of achieving its objectives easier and more quickly. The $\mathrm{EU}$ is essential for economic relations and may be in obtaining funds but more importantly it has a significant function for Turkey in achieving the great ideal of reaching contemporary civilisation as advanced by Atatürk.

When we view the situation from the EU perspective, clearly the European Union did not proclaim Turkey's candidacy out of its love for the Turks and neither will it accept Turkey on the basis of such affection. The EU has interests in being integrated with Turkey. A secular European Union is only possible with the accession of Turkey. Otherwise the EU will be a Christianity club. Having a few million Muslims living within its boundaries does not entitle the EU to view itself as a secular entity. The EU's secular nature shall only be guaranteed if a country like Turkey accedes to the Union. For the EU, an exchange with other civilisations rather than being merely enclaved in Western Europe and the Mediterranean region is only possible via Turkey. The EU can turn out to be a political-strategic actor not only in the European continent but also worldwide thanks to the accelerating motivation provided by a possible participation of Turkey.

Turkey is not an ordinary candidate country. The average population of all the other candidates is only six and a half million while Turkey alone has a population of almost seventy million. Turkey is itself a strategic actor in world affairs. Thus, Turkey does not need EU membership in order to secure a strategic position in the world arena. Membership, doubtlessly, will improve her position. Nevertheless, Turkey has always played a crucial role 
as a strategic actor when there was a problem in Macedonia, when people were being massacred in Kosova or when there was a conflict in Bosnia. Currently, Turkey is active in preventing war and in providing a humanitarian approach to the Middle East conflict. It is not possible for any other candidate country other than Turkey to command the international peace implementation force in Afghanistan. This makes Turkey a strategic power in itself. There are only a few countries which possess such power. Turkey has not been aware of this reality nor had it been reminded of such by others. However, this point is crucial for Turkey especially in her relations with the EU.

I was in Brussels four or five days before the Helsinki Summit. Mr. Verheugen, the Commissioner in charge of enlargement, invited me and my colleagues from the Foreign Ministry to an informal dinner. He was accompanied by two or three of his friends. I mentioned these concepts to him hoping that we would be persuaded to adopt a more favourable approach in the Helsinki Summit that was to be held a few days later. He told me "Mr. Cem, we are all aware of these points and if the EU announces your candidacy it will be exactly for the reasons you stipulated". In his speech at George Washington University three weeks later, Mr. Verheugen emphasised that Turkey's candidacy was important mainly for her strategic and historical position originating in Asia and extending into Europe and North Africa. Turkey adds something significant to Europe. Thus, it is not only the EU that will bring something to Turkey, but also that Turkey will offer something in return.

It is of course Turkey who wants to join the EU. We should not disregard this fact. The EU was established before we had any such intention and it has developed its own principles and rules whether we like and approve them or not. This is our own problem. If we really want to join it we have to observe these criteria. It is not possible to become a member of the EU by failing to fulfil them. Integration with the EU is not a must if these criteria are incompatible with structures existing in Turkey. This is a matter of choice based on its own logic. Turkey may choose to fulfil the criteria to become a part of the EU. This is another option. However, I see no logic in saying "we want to join the EU but we do not want to fulfil these principles". Turkey has to share these basic principles in order to become a part of the EU. If Turkey is not willing to share them, we should develop a more distant relationship with the EU. We have to consider this point seriously without supplying any demagogic interpretation. 
Let me mention to you one of the mistakes we make frequently. People think that radio and television broadcasting in other languages will be provided haphazardly and in all languages desired. People then reckon that everybody will be able to establish a television channel and broadcast and do whatever they wish and this will eventually lead to chaos. However, this is an incorrect scenario. Politicians, authors, the media are presenting a very extreme side to the situation. The European Union as a process, norm and understanding has its principles in such cases. The implementation of these principles may vary according to the leadership of the society which implements them.

As for the broadcasting issue, implementation varies in countries like France, Greece, Germany or the Scandinavian countries. Each has its own way of approaching the issue but without distorting the essentials of the principle. What we should do in Turkey is to handle the issue seriously and wisely by taking into consideration the reality of the situation in Turkey. The opposite is taking place. The wrong image has been created and it is over this that we have started to quarrel. We must overcome these fallacies because the relationship with the $\mathrm{EU}$ is a process based on a set of understandings and principles. Resolution will be automatic if you show determination and a good faith. On the other hand you face will have no way out if the problem is manipulated in an atmosphere of dispute. We are overlooking a specific point in Turkey when we start discussing freedoms and liberties and their expansion. We are always worried that these freedoms will be misused. I sometimes share the same feeling that liberties may be abused. However, the possibility of abuse should not let us limit or supress freedoms. The EU debate should not be a matter of dispute but a platform of conciliation in Turkey. We experienced this during the discussions over the Accession Partnership.

In the current coalition government everybody behaved sensibly by considering the vital issues at stake for other sections of the society, and eventually we managed to reach a policy reconciliation. This reveals that we can succeed. In our discussions over the $\mathrm{EU}$, it is not possible to reach a common point if people accuse each other of "not being in favour of democracy" etc. In solving problems concerning EU matters we always have to take into consideration the sensitivity of others who have views different from our own. We should always bear in mind that the EU itself is a 
platform of conciliation. This has become much clearer and it is a positive sign in our relations with the EU. Significant past disputes in Turkish-EU relations are now over. For example, I expressed myself very frankly-though not aggressively- in meetings and used to accuse the EU of behaving discriminatorily and unfairly against Turkey especially in the postLuxembourg and pre-Helsinki period.

Today my approach is more sensible in all issues except for the question of funds provided by the EU to candidate countries. I have criticised the EU policy of distributing these funds to candidate countries other than Turkey, but I must confess, Turkey has also her own shortcomings such as being disorganised and not being ready to propose suitable projects. I sometimes criticise the EU for behaving like a "colonial governer" but the European Union is itself a complex structure comprising different institutions. It involves fifteen member states and governments. The EU's approach is correct. It is time for Turkey to take a step forward. As soon as we finalise fulfilling the Copenhagen political criteria I will ask the EU to start negotiations at once. If the EU fails to start negotiations then I will be frank and fortright as in the pre-Helsinki period. However, we are far from that stage and it is up to Turkey to take a step forward. The EU has officially declared that as soon as Turkey fulfils the Copenhagen political criteria it would start negotiations. This was revealed by Mr. Verheugen in our joint press conference in Luxembourg. He even told us that "it is a matter of days" and then "months". He said he would bring the issue of opening negotiations with Turkey to the Council of Ministers if Turkey were to fulfil her obligations. Mr. Picquet following Mr. Verheugen reiterated the same thing. I cannot guarantee whether they will keep their promises but they made a commitment, an open declaration to do so.

The EU for us is a process of modernisation. Turkey's candidacy and membership process is simultaneous to her own modernisation process. The EU membership is a current stage in Turkey's process of modernisation. This process in Turkey started long before Turkey's candidacy or prior relations with the EU. The modernisation period in Turkish history cannot be confined exclusively to the era of Turkey-EU relations. We have to remember Ottoman history, Osman the Young, the Tanzimat (Reformation), the Meşrutiyet (Constitutional Government) periods and of course Kemal Atatürk... These periods were followed by the democratic transformation and the start of political pluralism in the 1960s. I mean that Turkey's modernisation is process and the EU is the current stage in that process. In 
Turkey, we have to define and implement it correctly. If Turkey cannot modernise herself then she will face difficulty in experiencing harmonious relations with the EU.

The issue of EU membership and Turkey's modernisation represent a single process. Turkey has both to entirely modernise her approach and herself. Turkey must have hope. Her modernisation should reflect the possibility of future compromise and not the conflicts of the past. The phenomenon of modernisation, of course, does not mean imitating others and abandoning self-identity as understood by some. Modernisation must be understood as the transformation of national values and unique characteristics into more contemporary and developed methods. Modernisation will help Turkey adapt itself to the EU and abandon some of the corrupt habits in its governance. By this I do not only refer to politics but also to the economy and old characteristics as well. They must be relegated to history and the most recent reforms must be accelerated. It is not possible to realise this adaptation with the EU unless both the private and public sectors renounce discord, corruption and distortion. Some positive results were achieved recently regarding the constitution and in the economy. These are favourable steps but are not sufficient. Further steps need to be taken to sustain the modernisation process.

Lastly, let me point out that Turkey considering her history, culture, people, youth and universities deserves better. We have to free ourselves from mistaken habits such as helplessness and self-hate. In Turkey, we have to extend the benefits of culture, education, prosperity and opportunities to larger parts of society. Turkey is able to do all of these things...The Turkish people deserve the best because they desire novelty and modernity. We are going to develop Turkey together on her way to the EU but more importantly on the way to her future. Thank you all for inspiring me to make these remarks. 